\title{
The University Illustration Merged in Thailand
}

\author{
Paithoon Puangyod ${ }^{1}$, Chaiyuth Sirisuthi ${ }^{2} \&$ Sumalee Sriphutharin ${ }^{1}$ \\ ${ }^{1}$ Faculty of Education, Nakhon-Phanom University, Thailand \\ ${ }^{2}$ Faculty of Education, Mahasarakham University, Thailand \\ Correspondence: Paithoon Puangyod, 178 M00 8 Nakhon-Phanom University, Thailand. Tel: 668-5646-2493. \\ E-mail: Paitoon_kanun@hotmail.com
}

Received: March 7, 2015 Accepted: April 30, 2015 Online Published: August 27, 2015

doi:10.5539/ies.v8n9p177 URL: http://dx.doi.org/10.5539/ies.v8n9p177

\begin{abstract}
This research aimed to reflect the merged university's scenario: the case study of Nakhon-Phanom University in 4 aspects: administration, personnel management, technology management and missions. It was divided into 2 parts. The research results were as follows: Part 1: Nakhon-Phanom University's education arrangement in light of the administration, personnel management, technology management and missions was explored. The education quality was found at a good level. Besides, its personnel viewed that the overall conditions and certain aspects of Nakhon-Phanom University were at an immediate intermediate level. Nonetheless, the mission, technology management, personnel management and administration were found according to the priority order. And Part 2: The pictures reflected by the experts for the development of Nakhon-Phanom University's fifteen-year scenario were as follows: the administration-Nakhon-Phanom University was an autonomous university that adopted flat organization structure with the application of moral system in the recruitment of senior- and middle-level administrators; the personnel management-good, knowledgeable, ethical and smart persons were expected. Moreover, the networks with other countries were developed. The instructors were also supported to further Ph.D.; the technology management-the networks and connectivity with the ASEAN member countries were created along with the development of the e-learning-based materials and classrooms; and the missions-the graduates with the desired characteristics were produced in response to the needs of the society, country and ASEAN member countries.
\end{abstract}

Keywords: futures research, higher education, EDFR technique

\section{Introduction}

\subsection{Introduce the Problem}

The human life has economic, social, cultural and political aspects., with science and technology linking the world together, the nature of the boundaries and the flow freely and as limitless as your knowledge. Education is an important mechanism of the development and progress of such. The report submitted to UNESCO, The International Commission on Education for the $21^{\text {st }}$ Century has proposed that learning continue throughout life. I turn the key one for the 21 st century is a concept that is far more responsive to the condition of a rapidly changing world. And to focus on the four pillars that are the foundation of the study were:

1) Learning to learn

2) Learning to practice

3) Learning to live together, and

4) Learning to live.

The focus is on both the demand and the quality and equality of educational opportunity, together with on the changing trends of the world in the 2020's (Siridrangsri, 2007). The Economist Intelligence Unit (2006) predict that in the next 15 years, the world economy undergo will significant changes linked to education and learning. This will depend on 5 key objectives: 1) Globalization: technological progress, capital market development and demographic changes to make the world into a big adjustment. Trade liberalization would make it more economical for companies move to Asia and India where costs are cheaper. Other countries have a comparative Low-cost and quality to sustain a 2) Working parts: industry products or services as a product or service is a product designed to provide specialized expertise more 3) regardless of the individual: the production and 
service will take into account the needs of the customer. The production of a dozen to fall 4) Movement of Population: The population is moving from child to young people aged up to 5) Knowledge Management. Will have a role in the organization and work more. Since its creation, publishing and seeking to expand their knowledge of personnel to specialize and increase in productivity. On the basis of the knowledge economy.

\subsection{Explore Importance of the Problem}

Despite the changes, developments and progresses of the Thai higher education in the past 10-20 years, it seemingly failed to respond to the social transitions. The strategic directions were thus determined in accordance with the Second 15-Year Long Range Plan on Higher Education of Thailand B.E. 2551-2565 (2008-2022). The Office of the Higher Education Commission (OHEC) under the auspices of the Higher Education Commission (HEC) and the Knowledge Network Institute of Thailand (KNIT) under the Ministry of University Promotion Foundation were the two agencies that collaboratively devised the Plan within the scope of Ministry of Education's policies. In particular, the strategic directions had two main parts. Firstly, it involved the analysis and reflection of the pictures and important implications, which were regarded as the surrounding factors affecting the human beings, the world, Thailand and higher education. Secondly, it concerned the internal factors of higher education system, present pictures and 7 aspects of the scenario: 1) demographic change, 2) energy and environment, 3) employment and future labor market, 4) conflict and violence management, 5) decentralisation, 6) Thai youth and students and 7) future graduates and the Philosophy of Sufficiency Economy.

\subsection{Describe Relevant Scholarship}

Nakhon-Phanom University was formed by the merger of 6 educational institutions in Nakhon-Phanom Province, namely, 1) Nakhon-Phanom Rajabhat University 2) Nakhon-Phanom Technical College, 3) Nakhon-Phanom College of Agriculture and Technology, 4) That Phanom Vocational College, 5) Nawa Vocational College and 6) Boromarajonani College of Nursing, Nakhon Phanom. Besides, Tourism and Service Industry College, International Aviation College and Language Institute were the faculty-level agencies founded by Nakhon-Phanom University Council. There were 18 public agencies under the auspices of Nakhon-Phanom University in 2013. The principles, philosophies and objectives of the instruction of Nakhon-Phanom University were in conformance with the cabinet resolution establishing Nakhon-Phanom University by the merger of the existing educational institutions for the maximization of the available resources with the minimum investment. Such merger was not in conflict with the education philosophy and the missions of the existing educational institutions that offered the associate degree programs (vocational and higher vocational degrees) and graduate degree programs.

\subsection{Hypothesis and Its Correspondence to Research Design}

The present trends had the great impact on the lifestyle and wellbeing of the world populations; therefore, the future directions of education were an important mechanism for human and country developments. As a result, those directions should be forward-looking and progressive for sustainability of lifestyle in the society. This conformed to Nakhon-Phanom University's philosophy stating that "Nakhon-Phanom University is a leading university in the Greater Mekong Sub-Region." The establishment of Nakhon-Phanom University was different from the other Thai universities so its education arrangement directions should suit the current situations by taking into account the future scenario. Nakhon-Phanom University should play a crucial role in steering and developing all sectors in a suitable manner that responded to the needs of faculty members, staffs, students and general publics. This aimed to be prepared for the future and to promote the reliability and the excellence in all aspects, which may be translated into a useful guidance for any university mergers in the future.

\section{The Purpose of the Study}

The purposes of the study were to assess the needs and the current situations of Nakhon-Phanom University and to propose a viable fifteen-year scenario for the University.

\section{Methodology}

This research was conducted into two periods, as follows.

\subsection{Period 1: Nakhon-Phanom University's Needs and Current Situations Were Explored Based on Its Personnel's Opinions}

\subsubsection{Research Methodology}

The documents and general data regarding Nakhon-Phanom University's performance were examined by means of a survey. This also included the examination of the Report on the Quality Assessment of Higher Education and Vocational Education, which was prepared by the Committee for the Internal Assessment of Education 
Quality. The initial data were analyzed and synthesized prior to the drafting of the research questions regarding Nakhon-Phanom University's scenario.

\subsubsection{Population and Sample Group}

The population consisted of a total of 710 personnel from 4 faculties and 6 colleges of Nakhon-Phanom University. They were the operational staffs, the instructors and the faculty members in the rank of vice rectors, deans and associate deans.

In order to examine Nakhon-Phanom University's needs and current situations, the samples were 250 staff members from 4 faculties and 6 colleges of Nakhon-Phanom University.

\subsubsection{Data Collection Tools}

The researcher- developed five-point Likert scale questionnaire was used in the data collection in Period 1. The collected data were based on 101 items of research frameworks regarding Nakhon-Phanom University's education arrangement. Besides, the conclusions drawn from the Assessment Report of the Office for National Education Standards and Quality Assessment (Public Organization) were also used by the researcher for developing the structured interview form.

\subsection{Period 2}

The study of Nakhon-Phanom University's viable fifteen-year scenario was conducted in consultation with the experts. In this regard, Ethnographic Delphi Futures Research (EDFR) was used in the determination of the research procedures (Chumphon Phoonphatarachiwin, n.d.: 261).

The research in Period 2 was conducted as follows:

Determination of Panel Experts: 5 groups of panel experts have been specified by the researcher, namely, 1) a group of administrators or former administrators (4 persons), 2) a group of the administrators or the former administrators of Nakhon-Phanom University (4 persons), 3) a group of vice rectors or former vice rectors (2 persons), 4) a group of senior experts or academicians with the knowledge and experience in higher education arrangement (4 persons), and 5) a group of graduates of Nakhon-Phanom University who have experience in the employment of graduates ( 3 persons)

The First Round of EDFR: The research results obtained from Period 1 were synthesized for the creation of Nakhon-Phanom University's fifteen-year scenario. The senior experts were also interviewed using the semi-structured interview forms.

The collection and analysis of the data collected in Period 1 were conducted with an aim to develop the five-point Likert scale questionnaire.

The Second Round of EDFR: The five-point Likert scale questionnaire was developed by the researcher to enable the experts to deliberate about the viability of Nakhon-Phanom University's fifteen-year scenario. Thus, the scenario developed in Period 1 was verified by the experts in light of its construct and content validity to ensure its consistency and suitability so that Nakhon-Phanom University's fifteen-year scenario would become more crystalized, correct and viable.

The collection and analysis of the data collected in Period 2 were conducted in order to develop the questionnaire for the third round of EDFR.

The Third Round of EDFR: To develop Nakhon-Phanom University's fifteen-year scenario, the adjusted version of Item 1.5 of the questionnaire and the experts' conclusions were used by the researcher as the guideline for enhancing the clarity, suitability and viability of Nakhon-Phanom University's scenario for the year B.E. 2570 (2027). The median, mode, range and quartile were used in classifying the group and position of each expert who responded to the questionnaires in the second round of EDFR. The statistical feedback of the entire group and the respondents' answers was also identified. The respondents were asked to reconsider their own answers before submitting them to the experts for comparing the consistency between those answers and the group's opinions. However, the experts would be requested to give the relevant explanations given that the inconsistency was found but the same answers were reconfirmed. All answers were then summarized for the development of Nakhon-Phanom University's scenario.

In this research, the panel experts consisted of specialists and senior experts with the experience in higher education arrangement. There were a total of 17 experts who were selected by means of purposive sampling.

The Semi-Structure Interview: This enabled the experts to share their opinions regarding Nakhon-Phanom University's viable and practical scenario. 
The Five-Point Likert Scale Questionnaire: This involved 4 aspects of Nakhon-Phanom University's scenario.

\section{Conclusions}

The research results in Period 1 (the examination of Nakhon-Phanom University's needs and current situations) could be summarized as follows:

\subsection{Administration}

According to the Report on the Quality Assessment of Higher Education, the administration of Nakhon-Phanom University was as follows: 1) The knowledge based on the personal experiences, documents and other sources should be gathered and systemized for publicization through a range of channels; 2) The strategic plans and annual action plans of each department were devised on the basis of the Risk Management Report's results, while the performance under the risk management plan was monitored and reported to the administrators on monthly, quarterly or yearly basis. This would enable the administrators or those who concerned in the risk management to assess the performance and provide the relevant advices in a timely manner. For the information systems, the information system networks should be available to facilitate the publicization of information and latest news the students via Web Boards, the university's website and the social media (Facebook). Additionally, Nakhon-Phanom University also had the internal public relations system facilitating the faculties'/colleges' publicization of general data related to the education systems and to Nakhon-Phanom University's internal/external affairs. Apart from the advices on the university affairs given by the advisers or the class teachers to the students, the guidance room and teacher's book were available for them too. The budget management in the Fiscal Year B.E. 2554 (2011) was according to the sources (income or national budget). The assessment of 9 elements and 42 indicators that was accepted by Nakhon-Phanom University was a part of its quality assurance system of higher education in the academic year of 2011. In this regard, the assessment of 9 quality elements revealed the results that were at a good level.

\subsection{Technology Management}

Besides, Nakhon-Phanom University's personnel management system also adopted the individual-based plans on the development, progress and life security of its personnel. Nonetheless, the budgetary constraints and a status of new-founded university were regarded as a hindrance to the full implementation of the training/field trip programs as well as the plans on furthering education, on the promotion to the academic/professional positions and on the increase of manpower.

\subsection{Personnel Management}

The examination of the bureaus or agencies under the auspices of Nakhon-Phanom University reflected the issues related to the education technology management system, the infrastructure, the use of technology and the social services. Nakhon-Phanom University had, currently, the problems in light of hardware, software, peopleware, database, network, policy and budget. All of them affected the development of information technology and communications.

\subsection{Mission}

The mission in light of the production of good and smart graduates with the desired characteristics in response to the communities' needs, it was found that learning promotion and development programs were arranged in 2011 for student promotions along with the provision of scholarships, grants for gifted students/cultural and art purposes and other grants. The techniques for knowledge and technology transfer to the communities were developed in an integrated manner through the Research and Development (R\&D) of innovations to meet the local demands and to enhance the competiveness in Greater Mekong Sub-Region. The research grants were from the internal and external sources. The academic service networks were created to serve as the academic and vocational service center that responded the needs of the society, country and Greater Mekong Sub-Region. Importantly, the development of vocational services in the field of environment and energy was recognized at the national level and in Greater Mekong Sub-Region. The academic and vocational service network was also developed at the organizational, communal and social levels in order to meet their respective needs, to strengthen their knowledge and to promote the local wisdoms based on the Philosophy of the Sufficiency Economy and Royally-Initiated Development Projects. This aimed to realize the development of the communities, country and Greater Mekong Sub-Region. Besides, the projects conducted in Nakhon-Phanom University were also on the basis of good governance principle. 
Research Results in Period 2: The Picture according to the Study of Nakhon Phanom's Scenario of Possible Instructions through Ethnographic Delphi Futures Research (EDFR)

- The management policy is devised in conformance with
the development directions of the country and Greater
Mekong Sub-Region.
- The administrators in all levels are recruited in a
transparent and fair manner.
- The flat organization approach is adopted.
- The management is based on the decentralization.
- Management Information System (MIS) is used.
- The budget management is transparent and accountable.
- There is the risk management.
- The public media is used in the active public relations.
- The internal agencies at all levels have their own quality
assurance. There are also personal indicators.

- Personnel development plan conforms to the university's missions and curriculums

- The instructors' external and internal networks are created.

- The instructors are encouraged and supported to enhance their education qualifications and academic titles.

- The 'Career Path' is provided for the instructors and supporting staffs.

- The personnel are supported and encouraged to attend the domestic and international field trips, seminars and training programs.

- There is a monitoring and assessment system of personnel performance.






\section{The Study of Nakhon-Phanom University's Current Situations:}

According to the data gathered by the researcher for the study of Nakhon-Phanom University's current situations, the overall performance and each aspect of administration were at the intermediate level. Meanwhile, the personnel management, the technology management and the missions were also at the intermediate level. Likewise, according to the survey of those who involved in the education arrangement, Nakhon-Phanom University's education arrangement was in average at the intermediate level in all aspects too.

\section{Discussion}

With regard to Nakhorn Phanom University's education arrangement in light of the administration, personnel management, technology management and missions, the overall quality of education was at a good level in conformance with the Committee for the Internal Assessment of Education Quality. The administrators had the leadership and determination to develop Nakhon-Phanom University into one of the leading higher education institutions in Greater Mekong Sub-Region. According to the interviews with the concerned persons, the rank in order from the most to the least was the missions, technology management, personnel management and administration, respectively. As a newly-founded university under Nakhon-Phanom University Act B.E. 2548 (2005), Nakhon-Phanom University was on the path towards becomming a comprehensive university. It still had a small amount of allotted budget when compared to the other public higher education institutes. Seemingly, Nakhon-Phanom University tended to be the last alternative for most students who failed the entrance exams for the other distinguished universities and had an average level of academic performance. The sample group also viewed that 4 aspects of Nakhon-Phanom University performance were at the intermediate level due to certain limitations, particularly the administration. This may probably be attributable to the size of Nakhon Phanom University that covered the entire province.

The research results discussed the following important issues.

\subsection{Administration}

As a public university, Nakhon-Phanom University's policies in the future should be devised in line with the development directions of the country and of the province cluster. The result- and performance-based management should be integrated into its internal management with the adoption of flat organization structure and function approach to enable the cross function. In addition, the decentralization of administration system should be realized using the bottom-up approach to vest the faculties a degree of management autonomy and authority. Nakhon-Phanom University's identity was translated into its prominent point. It also had academically-strengthened curriculums. Its administration system should be smaller and more flexible to reduce the processes with the efficient use of technologies in the university administration. The adjustment of its internal administration system, especially the structural arrangement for the empowerment of the operation units in making decisions to suit the changing situations was crucial. This conformed to the Office of Education Council, Ministry of Education (2009, pp. 5-6) that envisioned that, in the future, the education tended to play an increasingly important role and to be an important mechanism in the country development. Meanwhile, Moravec (2007, pp. 164-165) argued that the leaders of higher education institutes needed to integrate the paradigm change concepts with the ideologies, practices and activities for the success in the era of rapid changes, confusions and inaccuracies.

\subsection{Personnel Management}

In the future, Nakhon-Phanom University's internal plans for personnel development according to its prospective missions and curriculums were needed along with the recruitment of moral and proficient instructors who had the expertise in different disciplines. This included, for example, the recruitment of Ph.D. qualified instructors and more provision of Ph.D. grants for the instructors to further their specializations, especially the ones that Nakhon-Phanom University was notable for. The continual development of the instructors' potentials was conducted through the training programs, seminars and field trips (at the domestic and international levels). The internal and inter-university networks with the domestic and AEC universities were developed for promoting the instructors' collaborations. The university environment was created in a manner that facilitated the personnel's participation in the university development. The indicators and assessment system of the instructors' performance were adopted in the quality control. In addition, Nakhon-Phanom University's instructors may likely have a status of university employee in the future.

\subsection{Technology Management}

Nakhon-Phanom University had a future development plan of the technology infrastructure to connect with the internal and external networks, especially with the AEC member countries. The classrooms and e-Learning 
materials were developed with the use of the internal/external connectivity technologies so the high-speed internet system was the efficient channel facilitating the clients'/students' communications with the university and their university-wide data retrieval via the websites and web boards. There was an agency or a center responsible for the production of e-learning media and innovations. It served as the leader of the efficient information technology in conformance with the conclusion of the Office of the Higher Education Commission (OHEC) that concerned the implementation of Thai Learning Technologies (TLT) for the success of each strategy.

\subsection{Missions}

Nakhon-Phanom University needed to use its potentials in producing the vocational and high-vocational students and the graduates in response to the labor market demand and AEC integration e.g. the graduates fluent in Laotian, Vietnamese and Chinese languages. The alumni and current student database was created, while the university's identity was developed on the basis of its existing strengths. Besides, the human-oriented curriculum was introduced by taking into account the morality, ethics and public mind. The production of graduates in science disciplines should commence soon prior to the introduction of the Medicine Program. This conformed to the opinion of Duderstadt who claimed that the diverse university would be the future trend. The university should be able to respond to the social expansions that led to the increasing diversity of race, culture, economy, geography and minority groups. Moreover, the good governance was the foundation of the development allowing the people to work and live together in society.

\section{Acknowledgements}

The researchers would like to express our thanks and gratitude to Faculty of Education, Mahasarakham University, Thailand for financial support for this research paper.

\section{References}

Annelies, G., Mieke, C., Lies, L., \& Paul, P. (2008). Establishing a Competence Profile for Role of Student-centred Teachers in Higher Education in Belgium. Research in Higher Education, 49(6), 531-554.

Chaemchan, L. (1997). The Scenario for Prefessional Nursing Curriculum of the Nursing College Authorized by the Ministry of Public Health (Dissertation doctoral degree in Education, Higher Education Program, Graduates School, Srinakharinwirot University (Prasarnmit Campus)).

Charoenwongsak, K. (1998). The $5^{\text {th }}$ Wave, Social Sage: The Desired Thai Society in the $21^{\text {st }}$ Century. Bangkok: Success Media.

Damtew, T., \& Philip, G. A. (2004). African higher education: Challenges for the $21^{\text {st }}$ century. Higher Education, $47(1), 21-50$.

Krudmuang, S. (2004). An Administrative Model of the Autonomous State University (Dissertation of doctoral degree in Education, Education Administration Program, Graduates School, Naresuan University).

Office of the Higher Education Commission. (2003). Thai Higher Education in the World Higher Education. Bangkok: Faculty of Education, Chulalongkorn University.

Office of the Higher Education Commission. (2004). 2003 Education Quality Criteria for the Excellent Performance. Bangkok: Phap Printing.

Office of the Higher Education Commission. (2005). Thai Universities in Post World War II Era-The Changes towards the Modern Society. Bangkok: Active Print.

Office of the Higher Education Commission. (2006). Strategic Management Subject-The Development Programs for Education Administrator and Education Institute Administrators. Bangkok: Professional Development and Promotion Bureau.

Phoonphatarachiwin, C. (2004). Future Studies: Fundamental Knowledge and Understanding. Papers Presented in the Seminar "Trends of World Situations and the Future of Thai Education". 22 October 2004, Kaen Inn Hotel, Khon Kaen Province, Khon Kaen: Loei Rajabhat University.

Phoonphatarachiwin, C. (1986). Futures Research. Journal of Research Methodology, 1(1), 22-24.

Phoonphatarachiwin, C. (1987). EDFR Techniques. Journal of Social Sciences Research, 3(1), 34-57.

Phoonphatarachiwin, C. (2003). Ethnographic Delphi Futures Research. Encyclopedia of Education, Srinakharinwirot University, 18(30), 97-100.

Phoonphatarachiwin, C. (n.d.). EDFR Technique Ethnographic Delphi Futures Research (in the New Image of Policy Research for Determining the Future. Bangkok: The Social Science Research Association of 
Thailand, Education Research Department, Faculty of Education, Chulalongkorn University.

Phumkokrak, P. (2002). Governance Model for Chulalongkorn University in the Future. Education Information Resources Center, Faculty of Education, Chulalongkorn University.

Phumkokrak, P. (2007). Rajabhat University Management Approach under Rajabhat University Act B.E. 2547 (Dissertation of Doctoral Degree in Education, Chonburi, Burapha University).

Pilanthananon, N. (2003). Strategic Proposals and Directions for Thai Higher Education Reform. Bangkok: the Office of the Education Council, Ministry of Education.

Pilanthananon, N. (2008). Futurology. Bangkok: Odean Store Printing House, 1983. Office of the Education Council. The Framework for Education Development during the course of the $10^{\text {th }}$ National Economic and Social Development Plan (B.E. 2550-2554 / 2007-2011) in pursuance with National Educational Plan) B.E. 2545-2559/2002-2016). Bangkok: Chulalongkorn University Printing House.

Ruangwichathorn, P. (2008). Collective Power and Happiness-The Buddhist-Style Management for the Change-Agent Organization (2nd ed.). Bangkok: Sam Lada.

Secretariat Office of the Teachers Council of Thailand. (2006). Subject of Education Organization Management The Development Programs for Education Administrator and Education Institute Administrators. Bangkok: Professional Development and Promotion Bureau.

\section{Copyrights}

Copyright for this article is retained by the author(s), with first publication rights granted to the journal.

This is an open-access article distributed under the terms and conditions of the Creative Commons Attribution license (http://creativecommons.org/licenses/by/3.0/). 